\title{
Physical Self-Concept dan Body Mass Index: Hubungan dan Perbedaan berdasarkan Gender
}

\author{
Iman Ermawan ${ }^{\varpi}$, Jajat, Nana Sutisna \\ Pendidikan Jasmani Kesehatan dan Rekreasi, Universitas Galuh Ciamis
}

\begin{tabular}{l} 
Kata Kunci: \\
body mass index, gender, \\
physical self-concept, PSDQ, \\
remaja, siswa \\
\hline
\end{tabular}

\begin{abstract}
Penelitian ini bertujuan untuk mengkaji hubungan antara Physical SelfConcept (PSC) dengan Body Mass Index (BMI) serta perbedaan PSC dan BMI berdasarkan gender. Metode yang digunakan pada penelitian ini adalah assosiasonal (correlational dan kausal-komparatif). Sample berjumlah 59 orang siswa remaja SMA di Kabupaten Ciamis. Instrument yang digunakan untuk mengukur PSC adalah Physical Self Description Questionnaire (PSDQ). Untuk menguji hubungan antara PSC dan BMI digunakan koefisien korelasi, dan untuk uji beda digunakan independent sample t-test. Hasil pengolahan dan analisis menunjukan bahwa, (1) tidak ada hubungan yang signifikan antara PSC dan BMI ( $p>0.05)$; (2) tidak terdapat perbedaan BMI yang signifikan antara laki-laki dan perempuan ( $p>0.05)$; (3) terdapat perbedaan PSC yang signifikan antara laki-laki dan perempuan $(\mathrm{p}<0.05)$.
\end{abstract}

\section{Abstract}

This study aims to examine the relationship between Physical SelfConcept (PSC) and Body Mass Index (BMI) and differences in PSC and BMI based on gender. The method used in this study is associational (correlational and causal-comparative). Sample amounted to 59 high school teenagers in Ciamis Regency. The instrument used to measure PSC is Physical Self Description Questionnaire (PSDQ). To test the relationship between PSC and BMI used the correlation coefficient, and for the different tests used independent sample t-test. The results of processing and analysis show that, (1) there is no significant relationship between PSC and $B M I$ ( $p>0.05)$; (2) there was no significant difference in BMI between men and women ( $p>0.05$ ); (3) there are significant differences in PSC between men and women $(p<0.05)$..

(C) 2019 Universitas Pendidikan Indonesia

Alamat korespondensi:

Jl. Dr. Setiabudhi No. 229 Bandung, Jawa Barat

eISSN: 2549-6360

E-mail: iman.ermawan@gmail.com 


\section{PENDAHULUAN}

BMI merupakan ukuran yang digunakan untuk menilai proporsionalitas perbandingan antara tinggi dan berat badan seseorang. BMI adalah berat badan seseorang dalam kilogram dibagi dengan kuadrat tinggi dalam meter. Pengukuran ini pertama kali dijelaskan oleh Adolphus Quetelet pada pertengahan abad kesembilan belas berdasarkan pengamatan bahwa berat badan sebanding dengan tinggi kuadrat pada orang dewasa dengan kerangka tubuh yang normal (Corral et al, 2008). Seseorang yang kelebihan berat badan sangat rentan terhadap penyakit tertentu. Kondisi ini jika dibiarkan terus menerus dapat mempengaruhi kesehatan penderitanya.

Kondisi ini tidak hanya berdampak pada penampilan fisik penderitanya, tetapi juga meningkatkan risiko dalam kesehatan seperti penyakit jantung, diabetes, dan tekanan darah tinggi (Bays et al. 2007). Indonesia seperti negara berkembang lainnya menghadapi masalah gizi ganda pada kelompok usia remaja. Keadaan underweight, overweight, dan obesitas pada remaja akan berdampak pada peningkatan angka penderita penyakit dan kematian di usia dewasa. Badan Pusat Statistik (2013), memproyeksikan penduduk remaja Indonesia dengan umur 15 - 19 tahun pada tahun 2019 adalah sejumlah 222.942.000 penduduk, dengan 108.880 .000 perempuan dan 114.062.000 laki-laki.

Prevalensi obesitas di Indonesia menurut Riset Kesehatan Dasar (2018) pada remaja umur 15 - 18 tahun mengalami peningkatan dari tahun ke tahun. Di tahun 2018, prevalansi obesitas adalah sebesar 31.0, artinya

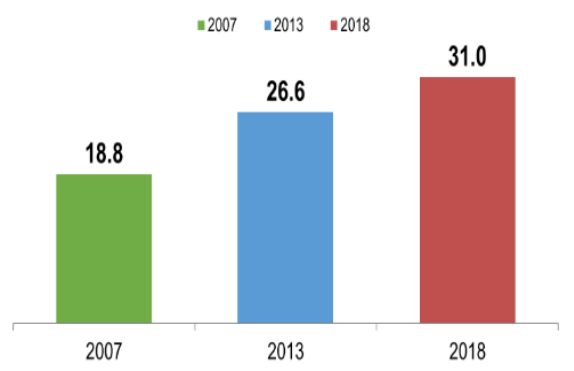

1 dari 4 orang remaja di Indonesia mengalami obesitas atau sekitar 69.112 .000 orang.

(Sumber: Riset Kesehatan Dasar 2018)

Obesitas sering dikaitkan dengan gangguan psikologis dan sosial seperti harga diri rendah dan konsep diri rendah, perasaan rendah diri, tidak ada kemampuan mengendalikan diri, depresi, perilaku anti sosial atau perilaku tidak aktif (Teixeira et al. 2012). Banyak penelitian telah menunjukkan bahwa orang dengan BMI tinggi atau orang gemuk menunjukkan konsep diri yang rendah. Anakanak yang mengalami obesitas memiliki kualitas hidup yang lebih rendah daripada anak-anak dan remaja yang sehat. (Schwimmer, Burwinkle, and Varni 2015).

Konsep diri sangat penting untuk kesejahteraan psikologis dan merupakan istilah yang digunakan untuk menggambarkan kesadaran individu tentang kualitas dan keterbatasan mereka (Jacobs et al. 2002). PSC memiliki korelasi positif dengan persepsi kesehatan, pengendalian diri, persepsi kesejahteraan, prestasi olahraga, motivasi dan prestasi, integrasi sosial dan sekolah. Di sisi lain, PSC memiliki korelasi negatif dengan kegagalan akademik, kecemasan, dan masalah dengan teman sebaya (Jesús \& Caballero 1998).

BMI yang tinggi harus diatasi karena bisa menambah risiko kematian. Resiko kematian akan meningkat dari semua penyebab penyakit kardiovaskular, kanker, atau penyakit lainnya pada orang yang memiliki berat badan berlebih baik untuk pria dan wanita di semua kelompok umur. Risiko yang terkait dengan BMI yang tinggi lebih besar untuk orang kulit putih daripada orang kulit hitam (Calle et al. 1999).

\section{METODE}

Metode yang digunakan adalah metode korelasi untuk mengetahui apakah terdapat hubungan antar variable dan metode kausalkomparatif untuk mengetahui perbedaan BMI dan PSC berdasarkan gender. Penelitian korelasional menyelidiki dua (atau lebih) variabel kuantitatif dan membutuhkan skor pada setiap variabel untuk setiap subjek. Studi 
kausal-komparatif biasanya membandingkan dua atau lebih kelompok subjek (Fraenkel, 2007)

\section{Partisipan dan Prosedur Pengambilan Data}

Partisipan dalam penelitian ini adalah 59 siswa SMA Kabupaten Ciamis. Untuk studi korelasional, jumlah sampel 50 dianggap perlu untuk membangun keberadaan suatu hubungan. Untuk studi kausal-komparatif, sample minimal adalah 30 individu di tiap kelompok, meskipun kadang-kadang studi eksperimental dengan hanya 15 individu di setiap kelompok dapat dipertahankan jika mereka sangat terkontrol (Fraenkel, 2007)

\section{Pengukuran Physical Self-Concept dan Body Mass Index}

Instrument yang digunakan untuk mengukur physical self-concept adalah versi pendek dari Phycisal Self Description Questionnaire (PSDQ; Marsh, 2010). PSDQ memiliki 9 skala spesifik untuk mengukur physical self-concept diantaranya; aktifitas, penampilan, lemak tubuh, koordinasi, daya tahan, kelenturan, kesehatan, kemampuan olahraga, kekuatan, dan 2 skala umum yaitu Global Physical dan Global Esteem.

\section{Analisis Statistika}

Pengolahan data menggunakan program SPSS Serie 22. Analisis koefisien korelasi digunakan untuk mengetahui hubungan antara PSC dan BMI. Untuk mengetahui perbedaan PSC dan BMI antara laki-laki dan perempuan digunakan analisis statistika independent sample t-test.

\section{HASIL DAN PEMBAHASAN}

Berdasarkan table 1 dapat dijelaskan bahwa data variable BMI dengan jumlah 59, nilai ratarata 21.82 dan nilai standar deviasi 3.30. Untuk variable PSC dengan jumlah sampel 59, nilai rata-rata 163.66 dan nilai standar deviasi 28.82 .

Tabel 1. Deskripsi Data

\begin{tabular}{lll}
\hline $\mathrm{N}$ & Mean & Std. Deviation \\
\hline
\end{tabular}

\begin{tabular}{cccc}
\hline BMI & 59 & 21.82 & 3.30 \\
\hline PSC & 59 & 163.66 & 28.82 \\
\hline
\end{tabular}

Tabel 2. Korelasi BMI dan PSC

\begin{tabular}{|c|c|c|c|}
\hline \multicolumn{4}{|c|}{ Correlations } \\
\hline & & & PSC \\
\hline \multirow[t]{3}{*}{$\begin{array}{l}\text { Kendall's } \\
\text { tau_b }\end{array}$} & BMI & $\begin{array}{l}\text { Coefficient } \\
\text { Correlation }\end{array}$ & -.104 \\
\hline & & Sig. (2-tailed) & .250 \\
\hline & & $\mathrm{N}$ & 59 \\
\hline
\end{tabular}

Dari tabel 2 terlihat bahwa nilai signifikansi BMI dengan PSC adalah sebesar $0.250>0.05$ sehingga ditemukan bahwa antara BMI dengan PSC tidak terdapat hubungan yang signifikan. Aktivitas fisik dan partisipasi olahraga dapat mengurangi risiko depresi di kalangan remaja perempuan dengan pengaruh unik dan positif pada physical self-concept (Dishman et al. 2006).

Olahraga teratur memiliki efek positif pada Physical self-concept (Tóth et al. 2019) dan Physical self-concept memiliki efek positif yang signifikan terhadap kebahagiaan psikologis (Kim 2018). Orang-orang yang melakukan latihan fisik secara teratur dan bersenang-senang dari waktu ke waktu cenderung memiliki physical self-concept yang lebih baik sehingga mereka memiliki kesejahteraan psikologis (Martín-Albo et al. 2012). Physical self-concept menjadi penentu penting aktivitas fisik remaja (Jekauc et al. 2017). Remaja dengan profil sikap positif lebih banyak terlibat dalam klub olahraga dan melaporkan physical self-concept yang lebih tinggi daripada remaja dengan profil sikap negative (Konowalczyk, Rade, and Mello 2019).

Tabel 3. Hasil Beda BMI berdasarkan gender

Independent Samples Test t-test for Equality of Means

Sig. (2-

$\mathrm{t}$ df tailed)




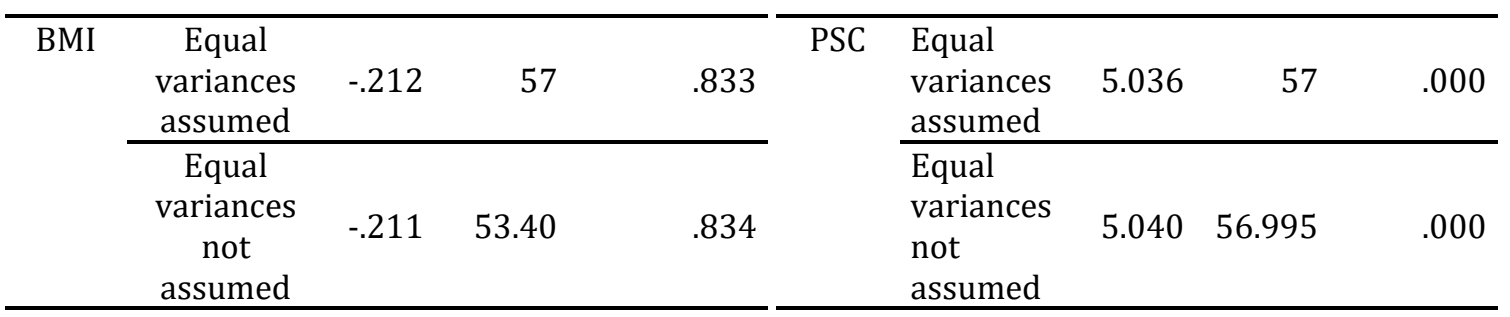

Dari tabel 3, nilai Signifikansi $0.833>$ 0.05 diketahui bahwa tidak terdapat perbedaan BMI yang signifikan antara laki-laki dan perempuan. Anak-anak dan remaja yang kelebihan berat badan atau obesitas memiliki tingkat kebugaran jasmani lebih rendah dibandingkan dengan teman mereka yang memiliki berat badan normal. Program aktivitas fisik yang terstruktur dapat menurunkan kelebihan berat badan atau obesitas sehingga perlu ditekankan untuk populasi ini.

Tingkat intensitas aktivitas fisik yang lebih tinggi mampu meningkatkan kebugaran jasmani dan mencegah atau mengurangi kelebihan berat badan di kalangan anak-anak dan remaja (Aires et al. 2010). Pembuat kebijakan pendidikan dan guru Pendidikan Jasmani harus menerapkan strategi untuk mempromosikan aktivitas fisik di sekolah dan menyediakan program Pendidikan Jasmani berkualitas untuk meningkatkan aktivitas fisik selama masa remaja (Fernández-bustos 2019).

Sekolah dapat memainkan peran penting dengan mengidentifikasi anak-anak dengan kebugaran fisik yang rendah dan dengan mempromosikan perilaku kesehatan yang positif seperti mendorong anak-anak untuk aktif, dengan penekanan khusus pada intensitas kegiatan. peningkatan kebugaran kardiorespirasi memiliki efek positif pada depresi, kecemasan, suasana hati, self esteem, dan tampaknya juga dikaitkan dengan kinerja akademik yang lebih tinggi (Ortega et al. 2008).

Tabel 4. Hasil uji t PSC berdasarkan gender

Independent Samples Test t-test for Equality of Means

Sig. (2-

$\mathrm{t} \quad \mathrm{df} \quad$ tailed)

Dari table 4, nilai Signifikansi $0.00<0.05$ diketahui bahwa terdapat perbedaan PSC yang signifikan antara laki-laki dan perempuan. Laki-laki umumnya memiliki penilaian yang lebih tinggi di seluruh dimensi physical selfconcept daripada perempuan. Laki-laki dan perempuan berbeda satu sama lain tentang bagaimana mereka memandang diri mereka sendiri pada berbagai dimensi (Caglar 2015).

Physical self-concept secara signifikan lebih tinggi pada anak laki-laki daripada perempuan di delapan subdomain, serta global physical self-concept dan self-esteem. Physical self-concept menurun dengan bertambahnya usia, dan ada usia yang signifikan oleh interaksi gender dalam global physical, lemak tubuh, penampilan, kompetensi olahraga, dan dimensi kekuatan. Penampilan fisik adalah subdomain yang paling kuat meramalkan global self-esteem (Shiomori et al. 2000). Partisipasi olahraga memiliki efek yang lebih besar pada kepuasan tubuh positif di kalangan anak laki-laki (Gomezbaya, Mendoza, and Matos 2017).

Anak laki-laki memiliki kepercayaan diri dan kompetensi olahraga yang lebih besar dibandingkan dengan anak perempuan, sedangkan anak perempuan memiliki persepsi yang lebih baik tentang penampilan fisik dan kekuatan fisik daripada anak laki-laki. Semakin baik konsep diri fisik, semakin sedikit kegemukan yang ditemukan pada laki-laki dan perempuan (Zsakai et al. 2015).

\section{KESIMPULAN}

Berdasarkan pengolahan data hasil penelitian disimpulkan bahwa tidak ada hubungan yang signifikan antara PSC dan BMI, tidak terdapat perbedaan BMI yang signifikan antara laki-laki dan perempuan, tetapi terdapat perbedaan PSC yang signifikan antara laki-laki dan perempuan. 


\section{DAFTAR PUSTAKA}

Aires, L. et al. 2010. "A 3-Year Longitudinal Analysis of Changes in Body Mass Index." International Journal of Sports Medicine 31(2): 133-37.

Bays, H E, R H Chapman, S Grandy, and Investigators Group. 2007. "The Relationship of Body Mass Index to Diabetes Mellitus, Hypertension and Dyslipidaemia : Comparison of Data from Two National Surveys." (May): 737-47.

Bps, Katalog. 2013. Proyeksi Penduduk Indonesia Indonesia. Jakarta: Badan Pusat Statistik.

Caglar, Emine. 2015. "Similarities and Differences in Physical Self-Concept of Males and Females during Late Adolescence and Early Adulthood SIMILARrnES AND DIFFERENCES IN PHYSICAL SELF- CONCEPT OF MALES AND FEMALES DURING LATE ADOLESCENCE AND EARLY ADULTHOOD Emine Çaglar." (June 2009).

Calle, Eugenia E. et al. 1999. "BODY-MASS INDEX AND MORTALITY IN A PROSPECTIVE COHORT." : 1097-1105.

Dishman, Rod K et al. 2006. "Physical SelfConcept and Self-Esteem Mediate CrossSectional Relations of Physical Activity and Sport Participation With Depression Symptoms Among Adolescent Girls." 25(3): 396-407.

Fernández-bustos, Juan Gregorio. 2019. “Effect of Physical Activity on Self-Concept: Theoretical Model on the Mediation of Body Image and Physical Self-Concept in Adolescents." 10(July).

Gomez-baya, Diego, Ramon Mendoza, and Margarida Gaspar De Matos. 2017. "Sport Participation , Body Satisfaction and Depressive Symptoms in Adolescence: A Moderated-Mediation Analysis of Gender Differences." European Journal of Developmental Psychology 5629(September): https://doi.org/10.1080/17405629.2017. 1364988.

Jack R. Fraenkel,. Norman E. Wallen, Helen H. Hyun. 2007. 136 Journal of Experimental Psychology: General HOW TO DESIGN AND EVALUATE RESEARCH IN EDUCATION.

Jacobs, Janis E. et al. 2002. "Changes in Children's Self-Competence and Values:
Gender and Domain Differences across Grades One through Twelve." Child Development 73(2): 509-27.

Jekauc, Darko et al. 2017. “Does Physical SelfConcept Mediate the Relationship between Motor Abilities and Physical Activity in Adolescents and Young Adults ?" : 1-18.

Jesús, María, and Cava Caballero. 1998. "LA POTENCIACIÓN DE LA AUTOESTIMA.”

Kemenkes, Badan Penelitian dan Pengembangan Kesehatan. 2018. HASIL UTAMA RISKESDAS 2018.

Kim, Hyunsook. 2018. "The Effect of Physical Self-Concept on Sportswear Dependence and Psychological Happiness Hyunsook." Journal of the Korean Society of Clothing and Textiles 42(6): 1039-55.

Konowalczyk, Svenja, F Clemens A Rade, and Zena R Mello. 2019. "Time Perspective, Sports Club Membership, and Physical Self- Concept among Adolescents: A Person-Centered Approach." Journal of Adolescence 72(July 2018): 141-51. https://doi.org/10.1016/j.adolescence.20 19.02.008.

Marsh, Herbert W. 2010. "Introducing A Short Version of the Physical Self Description Questionnaire." : 438-82.

Martín-Albo, José et al. 2012. "Relationships between Intrinsic Motivation, Physical Self-Concept and Satisfaction with Life: A Longitudinal Study." Journal of Sports Sciences 30(4): 337-47.

Ortega, F. B., J. R. Ruiz, M. J. Castillo, and M. Sjöström. 2008. "Physical Fitness in Childhood and Adolescence: A Powerful Marker of Health." International Journal of Obesity 32(1): 1-11.

Romero-Corral, A. et al. 2008. "Accuracy of Body Mass Index in Diagnosing Obesity in the Adult General Population." International Journal of Obesity 32(6): 959-66.

Schwimmer, Jeffrey B, Tasha M Burwinkle, and James W Varni. 2015. "Health-Related Quality of Life of Severely Obese Children and Adolescents." 289(14): 1813-19.

Shiomori, Teruo, Shin ichi Yoshida, Hiroshi Miyamoto, and Kazumi Makishima. 2000. "Physical Self-Concept and Sports: Do Gender Differences Still Exist?" Journal of Allergy and Clinical Immunology 105(3): 449-54.

Teixeira, Pedro J. et al. 2012. "Motivation, SelfDetermination, and Long-Term Weight 
Control." International Journal of Behavioral Nutrition and Physical Activity 9(1):

22. http://www.ijbnpa.org/content/9/1/22.

Tóth, László et al. 2019. "Original Article Exercise Involvement and Trait-Anxiety Are Determinants of Physical Self-
Concept: Exercisers Exhibit Superior Profiles Compared with Non-Exercisers." 19(1): 580-85.

Zsakai, Annamaria, Zsolt Karkus, Katinka Utczas, and Eva B Bodzsar. 2015. "Body Structure and Physical Self-Concept in Early Adolescence." 